\title{
Numb Regulates the Polarized Delivery of Cyclic Nucleotide- Gated Ion Channels in Rod Photoreceptor Cilia
}

\author{
Vasanth Ramamurthy, ${ }^{1,2}$ Christine Jolicoeur, ${ }^{1}$ Demetra Koutroumbas, ${ }^{1,3}$ Johanna Mühlhans, ${ }^{4}$ Yun-Zheng Le, ${ }^{5}$ \\ William W. Hauswirth, ${ }^{6}$ (1) Andreas Giessl, ${ }^{4}$ and Michel Cayouette ${ }^{1,2,3,7}$ \\ ${ }^{1}$ Institut de recherches cliniques de Montreal, Montreal, Quebec H2W 1R7, Canada, ${ }^{2}$ Division of Experimental Medicine and ${ }^{3}$ Department of Anatomy and \\ Cell Biology, McGill University, Montreal, Quebec H3A 2B2, Canada, ${ }^{4}$ Department of Biology, Animal Physiology, University of Erlangen-Nuremberg, 91058 \\ Erlangen, Germany, ${ }^{5}$ Department of Medicine and Harold Hamm Diabetes Center, University of Oklahoma Health Sciences Center, Oklahoma City, \\ Oklahoma 73104, ${ }^{6}$ Department of Ophthalmology and Powell Gene Therapy Center, University of Florida, Gainesville, Florida 32610, and ${ }^{7}$ Department of \\ Medicine, Université de Montréal, Montreal, Quebec, H3T 1P1 Canada
}

The development and maintenance of protein compartmentalization is essential for neuronal function. A striking example is observed in light-sensing photoreceptors, in which the apical sensory cilium is subdivided into an inner and outer segment, each containing specific proteins essential for vision. It remains unclear, however, how such polarized protein localization is regulated. We report here that the endocytic adaptor protein Numb localizes to the inner, but not the outer segment of mouse photoreceptor cilia. Rod photoreceptorspecific inactivation of numb in vivo leads to progressive photoreceptor degeneration, indicating an essential role for Numb in photoreceptor cell biology. Interestingly, we report that loss of Numb in photoreceptors does not affect the localization of outer segment disk membrane proteins, such as rhodopsin, Peripherin-rds, Rom-1, and Abca4, but significantly disrupts the localization of the rod cyclic nucleotide-gated (Cng) channels, which accumulates on the inner segment plasma membrane in addition to its normal localization to the outer segments. Mechanistically, we show that Numb interacts with both subunits of the Cng channel and promotes the trafficking of Cngal to the recycling endosome. These results suggest a model in which Numb prevents targeting of Cng channels to the inner segment, by promoting their trafficking through the recycling endosome, where they can be sorted for specific delivery to the outer segment. This study uncovers a novel mechanism regulating polarized protein delivery in light-sensing cilia, raising the possibility that Numb plays a part in the regulation of protein trafficking in other types of cilia.

Key words: cilia; numb; photoreceptors; polarity; retina; trafficking

\section{Introduction}

Neuronal function critically depends on the establishment and maintenance of different cellular compartments containing a specific set of proteins. One of the most striking examples of polarized protein localization is observed in photoreceptor cells of the mammalian retina. The light-sensing cilium, which forms the apical domain, is subdivided into two parts: the inner segment (IS), where protein synthesis takes place, and the outer

\footnotetext{
Received May 13, 2014; revised Aug. 14, 2014; accepted Sept. 9, 2014.

Author contributions: V.R. and M.C. designed research; V.R., C.J., D.K., J.M., and A.G. performed research; Y.Z.-L. and W.W.H. contributed unpublished reagents/analytic tools; V.R., C.J., A.G., and M.C. analyzed data; V.R. and M.C. wrote the paper.

This work was supported by operating grants from the Canadian Institutes of Health Research and the Foundation Fighting Blindness Canada. V.R. received studentships from the Foundation Fighting Blindness Canada and the Fonds de recherche du Québec-Santé. M.C. is a Senior Fellow of the Fonds de recherche du Québec-Santé/Fondation Antoine-Turmel. We thank Robert Molday for the Cnga1, Abca4, Rom-1, Peripherin/rds, and rhodopsin antibodies, Stylianos Michalakis for the Cngb1 antibody, and Jeremy Nathans for the photoreceptor-specific cadherin antibody; Nadja Schröder-Kre $\beta$ for technical assistance with EM, Marie-Claude Bélanger for help with in vivo electroporations, and Jessica Barthe and Marie-Andrée Marcotte for animal colony management.

The authors declare no competing financial interests.

Correspondence should be addressed to Dr Michel Cayouette, IRCM, 110 Avenue des Pins Ouest, Montreal, QC H2W 1R7, Canada. E-mail: michel.cayouette@ircm.qc.ca.

DOI:10.1523/JNEUROSCI.1938-14.2014

Copyright $\odot 2014$ the authors $\quad 0270-6474 / 14 / 3413976-12 \$ 15.00 / 0$
}

segment (OS), where proteins of the phototransduction cascade specifically localize (Fig. $1 A$ ).

Much has been learned over the past years on the mechanisms regulating the transport of the photopigment rhodopsin to the OS (Sung and Chuang, 2010; Deretic and Wang, 2012), but less is known about how other OS-specific proteins are trafficked. Although it was originally proposed that other OS proteins might "piggyback" on rhodopsin and be transported along the same route (Papermaster, 2002), various evidence suggest that this is most likely not the case. First, many mouse mutants presenting rhodopsin trafficking defects have normal localization of other OS proteins (Insinna and Besharse, 2008; Sung and Chuang, 2010). Second, artificial detachment of the OS leads to accumulation of rhodopsin and the structural OS protein Peripherin/rds in the IS, but at different subcellular locations (Fariss et al., 1997; Lee et al., 2006). Although these observations suggest the existence of alternative sorting mechanisms for other OS proteins, these remain to be identified.

The cyclic nucleotide-gated (Cng) channel specifically localizes to the OS and plays a key part during phototransduction by closing in response to light to prevent $\mathrm{Ca}^{2+}$ and $\mathrm{Na}^{+}$influx and trigger hyperpolarization. Unlike rhodopsin, which localizes to the disk membranes of OS, the Cng channel localizes on the 


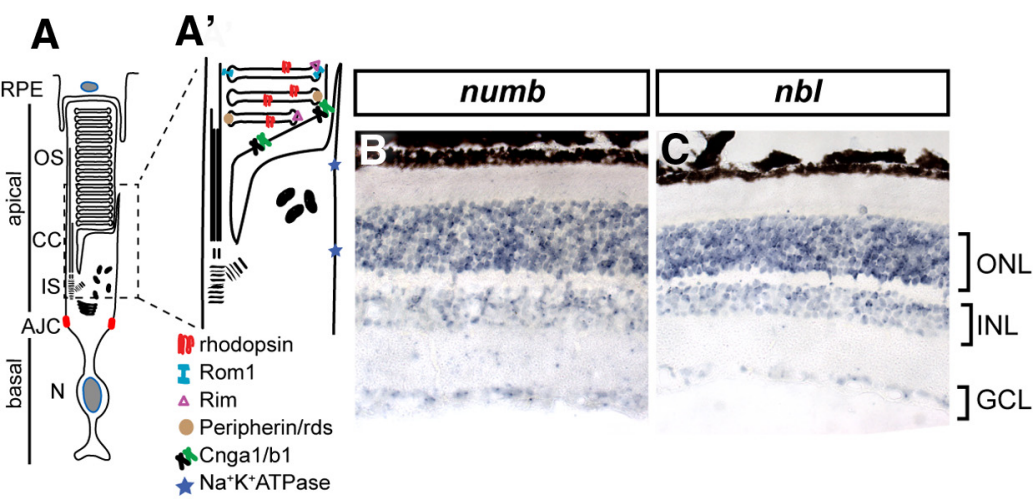

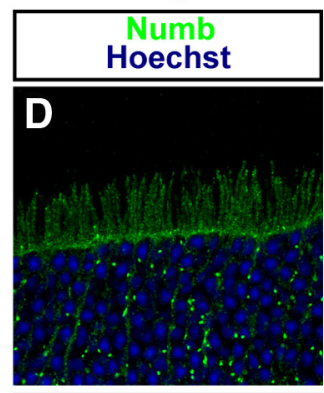
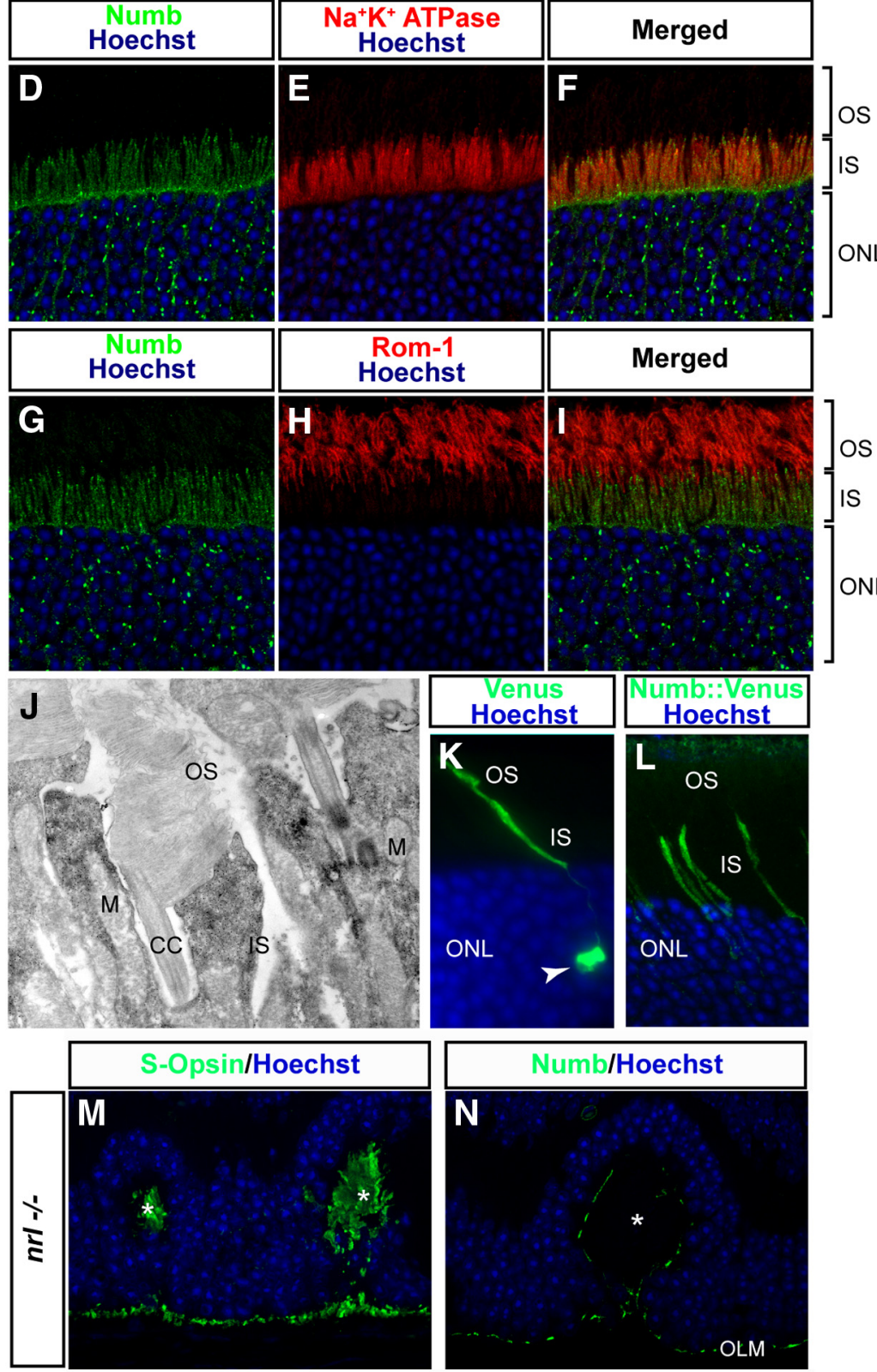

Figure 1. Numb/NbL expression in the adult retina. $A$, Schematic representation of a rod photoreceptor cell depicting the apical and basolateral membrane separated by the apical junctional complex (AJC). $\boldsymbol{A}^{\prime}$, A magnified view of the region boxed in $\boldsymbol{A}$ showing subcellular localization of some proteins studied in this study. RPE, Retinal pigmented epithelium; CC connecting cilium; N, nucleus; S, synaptic terminal. $\boldsymbol{B}, \boldsymbol{C}$, In situ hybridization with antisense probes for numb and $n b /$ on mouse retinal sections at $P 60$. Specific signal is seen in the outer nuclear layer (ONL), inner nuclear layer (INL), and ganglion cell layer (GCL). The ONL contains cell bodies of photoreceptors, whereas the INL contains cell bodies of interneurons and Müller glia. D-I, Coimmunostaining of mouse retinal sections at P60, as indicated. J, Electron micrographs of immuno plasma membrane surrounding the OS (Fig. 1 $A^{\prime}$ ). The functional channel is composed of three $\alpha$ (Cngal) and one $\beta$ (Cngb1) subunit in rod photoreceptors (Zhong et al., 2002), and although formation of a heteromeric complex, as well as the adaptor protein Ankyrin-G, were shown to be required for its transport to the OS (Hüttl et al., 2005; Zhang et al., 2009; Kizhatil et al., 2009), the mechanisms controlling the sorting and exclusive polarized localization of the channel to the OS plasma membrane remain unknown.

Recently we reported that the endocytic adaptor protein Numb, which is known to bind the endocytic protein Eps15 and the clathrin adaptor AP-2 (Salcini et al., 1997; Santolini et al., 2000), is essential for the production of terminal asymmetric cell divisions in the developing mouse retina (Kechad et al., 2012). During the course of this study, we noted that Numb expression is maintained in adult photoreceptors, and whereas Numb function has been extensively studied during development, its role in mature neurons in vivo remains largely unknown. We report here that Numb and its homolog Numblike (NbL) are essential for photoreceptor cell survival and for the polarized sorting of Cng channels to the OS. We find that Numb interacts with both subunits of the rod Cng channel, and promotes trafficking of Cngal to the recycling endosome. In the absence of Numb, the Cng channel is no longer exclusively localized to the OS, and additionally accumulates on the IS plasma membrane. Together, these results suggest a model in which Numb functions as an adaptor protein regulating the efficient targeting of the Cng channel to the recycling endosome, where it can be sorted for specific delivery to OS plasma membrane.

\section{$\leftarrow$}

staining for Numb on $\mathrm{P} 60$ retinas. DAB precipitates were silver intensified and appear as black dots on the image. Numb is found throughout the IS, but not the $0 \mathrm{~S}$ or $\mathrm{CC}$ and mitochondria (M). $K, \boldsymbol{L}$, In vivo electroporation of a control Venus protein $(\boldsymbol{K})$ or a Numb::Venus fusion $(\boldsymbol{L})$ in photoreceptor cells at P30. Venus is found in the cell body (arrow), as well as the IS and OS, whereas Numb::Venus localizes only in the IS. $\boldsymbol{M}, \mathrm{S}$-Opsin staining in Nrl knock-out $\left(\mathrm{nrl}^{-1-}\right)$ retinas. These retinas contain only cones that often organize in rosettes (asterisks), in which the IS/OS are found. The cone $0 S$ are identified by S-Opsin signal in the rosettes (asterisks). $\mathbf{N}$, In contrast, no Numb staining is observed in the $\mathrm{IS} / \mathrm{OS}$ regions of $\mathrm{nr}^{-1-}$ retina (asterisk). The only Numb staining observed is in the outer limiting membrane (OLM), which is also observed in wild-type retinas. 
Table 1. Primary antibodies used in this study

\begin{tabular}{|c|c|c|c|c|c|}
\hline Antigen & Antibody name & Species & Dilution & Source & References (if any) \\
\hline rhodopsin & $4 \mathrm{D} 2$ & Mouse & $1 / 20(I)$ & R. Molday (UBC, Vancouver, Canada) & (Hicks and Molday, 1986) \\
\hline Cnga1 & Pmc1d1 & Mouse & $\begin{array}{c}1 / 20 \text { (I); } 1 / 30(\mathrm{~W}) ; 10 \mathrm{ml} \\
\text { (IP); } 1: 20-50 \text { (IEM) }\end{array}$ & R. Molday & (Cook et al., 1989) \\
\hline Abca4 & $3 F 4$ & Mouse & $1 / 20(\mathrm{I})$ & R. Molday & (Illing et al., 1997) \\
\hline Rom1 & $1 \mathrm{D} 5$ & Mouse & $1 / 20(I)$ & R. Molday & (Moritz and Molday, 1996) \\
\hline Peripherin/rds & Per5H2 & Mouse & $1 / 20(\mathrm{I})$ & R. Molday & (Connell et al., 1991) \\
\hline Actin & & Mouse & $1 / 10,000(W)$ & Sigma-Aldrich, A5441 & \\
\hline $\mathrm{Na}^{+} / \mathrm{K}^{+}$ATPase & & Mouse & $1 / 100(I)$ & Thermo Scientific, MA3-915 & \\
\hline Numb & & Rabbit & $1 / 100(\mathrm{I}) ; 1 \mu \mathrm{g} / \mathrm{ml}(\mathrm{W})$ & Abcam, 14140 & \\
\hline Pr-cadherin & & Rabbit & $1 / 100(I)$ & J. Nathans (Johns Hopkins University, Baltimore, MD) & (Rattner et al., 2001) \\
\hline GFP/Venus & & Rabbit & $1 / 1000(\mathrm{I}) ; 1 / 5000(\mathrm{~W}) ; 3 \mu \mathrm{g}(\mathrm{IP})$ & Invitrogen, A11122 & \\
\hline Cngb1 & & Rabbit & $1 / 500(I)$ & S. Michalakis (Ludwig-Maximilians-Universität München, Munich, Germany) & (Hüttl et al., 2005) \\
\hline
\end{tabular}

Dilutions used for immunostaining (I), Western blotting (W), immunoprecipitation (IP) and immunoelectron microscopy (IEM) are shown.

\section{Materials and Methods}

Animals

All animal work was carried in accordance with the Canadian Council on Animal Care guidelines. The Opsin-Cre (Le et al., 2006) and numb/nbl floxed (Wilson et al., 2007) mouse lines were used to generate photoreceptor-specific cDKO. Both heterozygotes and Cre-negative animals were used as controls in this study and referred to as "control" throughout the text and figures. Animals of either sex were used in this study.

\section{Probes and in situ hybridization}

Digoxigenin-labeled RNA probes were synthesized from full-length cDNA template of numb and numblike. Eyes were collected, fixed in PFA $4 \%$ overnight, frozen in OCT, sectioned, and air-dried for $30 \mathrm{~min}$. Hybridization was done at $65^{\circ} \mathrm{C}$ overnight with $300 \mathrm{ng} / \mathrm{ml}$ of RNA probes in the hybridization buffer $(50 \%$ formamide, $5 \times$ SSC, $5 \times$ Denhardt's, 5 $\mathrm{mg} / \mathrm{ml}$ of Torula RNA, $500 \mu \mathrm{g} / \mathrm{ml}$ fish sperm DNA). The probes were detected with an anti-Dig-AP antibody (1:3500, Roche). The AP activity was revealed using the nitro blue tetrazolium chloride/5-bromo-4chloro-3'-indolyphosphate substrate (NBT/BCIP, Roche).

Histology, immunohistochemistry, and electron microscopy

PFA was used as a fixative for all histology and immunohistochemistry, with the exception of tissue used for EM. Eyes were enucleated and fixed by immersion in freshly prepared $4 \%$ paraformaldehyde in PBS for $3 \mathrm{~h}$ on ice, cryoprotected in sucrose $20 \%$ overnight, and cryosectioned. Sections were preincubated for $1 \mathrm{~h}$ in blocking buffer (20\% goat serum in $0.2 \%$ Triton) and then incubated overnight at $4^{\circ} \mathrm{C}$ with the primary antibodies (Table 1). The Numb antibody used (Abcam) also cross-reacts with NbL (Kechad et al., 2012).

\section{Electron microscopy}

Retinas from adult mice [postnatal day (P)150] were dissected, cut into small pieces, and fixed in $2.5 \%$ glutaraldehyde in $0.1 \mathrm{M}$ sodium cacodylate buffer with $4 \%$ sucrose overnight at $4^{\circ} \mathrm{C}$. The next day, the tissues were washed with $0.1 \mathrm{~m}$ sodium cacodylate buffer, and postfixed in cold $1 \%$ buffered $\mathrm{OsO} 4$ and $1.5 \%$ aqueous potassium ferrocyanide for $2 \mathrm{~h}$ at $4^{\circ} \mathrm{C}$. Then, tissues were dehydrated in increasing concentrations of acetone and embedded in Epon 812. Sectioning for electron microscopy examination followed standard procedures on an ultramicrotome (Reichert Ultra Cut AV Ultramicrotome). Blocks of retinas were then cut again and thin sections (60-80 nm thick) were stained in $4 \%$ uranyl acetate for 5 min, Reynolds' lead for $3 \mathrm{~min}$, and viewed under a transmission electron microscope (FEI, Titan Krios).

\section{Pre-embedding immunoelectron microscopy}

Vibratome sections were blocked in $10 \%$ normal goat serum and $1 \%$ bovine serum albumin in PBS for $2 \mathrm{~h}$. Sections were incubated with the primary antibody for $4 \mathrm{~d}$ at $4^{\circ} \mathrm{C}$. After four $15 \mathrm{~min}$ PBS washes, binding of the primary antibody was visualized with a biotinylated goat anti-rabbit IgG (or anti-mouse IgG) secondary antiserum (Vector Laboratories) diluted 1:100 and a peroxidase-based enzymatic detection system (Vec- tastain Elite ABC kit; Vector Laboratories). The provided avidin-biotin HRP complex (ABC) binds the biotinylated secondary antibodies. This immunocomplex was visualized by adding $0.01 \%$ hydrogen peroxide to a $0.05 \% 3.3^{\prime}$-diaminobenzidine (DAB) solution. The staining was fixed by incubation in $2.5 \%$ glutaraldehyde in cacodylate buffer $(0.1 \mathrm{M}, \mathrm{pH} 7.4)$ for $1 \mathrm{~h}$. DAB precipitates were silver intensified and sections were finally incubated in $0.5 \% \mathrm{OsO} 4$ in cacodylate buffer for $30 \mathrm{~min}$ at $4^{\circ} \mathrm{C}$. After washing and dehydration, vibratome sections were flat-mounted between two sheaths of heat-resistant transparency film in Epon. Ultrathin sections were examined and photographed with a Zeiss EM10 electron microscope and a GATAN SC1000 OriusTM CCD camera in combination with the DigitalMicrographTM software (GATAN). Images were adjusted for contrast and brightness using Adobe Photoshop CS6.

\section{In vivo electroporation}

DNA preparations were injected subretinally at P0 according to a modified procedure previously described (Matsuda and Cepko, 2004). The volume of the injection was maintained between 0.5 and $1 \mu \mathrm{l}$. After the injection, tweezer-type electrodes, (Gene paddles, $3 \times 5 \mathrm{~mm}$ Paddles Model 542, Harvard Apparatus) soaked in PBS were placed on either side of the head of the pup and five square pulses of $50 \mathrm{~ms}$ duration with 950 $\mathrm{ms}$ intervals were applied using a pulse generator (ECM 830 Square Wave Electroporation System, Harvard Apparatus). The eyes were collected at $\mathrm{P} 21$, fixed, and processed for immunostaining as described above.

\section{Transfections and constructs}

COS-7 cells were transfected with Lipofectamine using the following constructs: Rab11::DsRed (Addgene plasmid 12679, generated by Richard Pagano, Mayo Clinic and Foundation, Rochester, MN 55905; Choudhury et al., 2002), pCAGS-Cnga1, or Numb::Myc. Cells were fixed $24 \mathrm{~h}$ after transfection and stained with anti-Cngal, and imaged using a Zeiss LSM 710 confocal microscope or Leica epifluorescence microscope followed by image deconvolution.

\section{Quantification}

Photoreceptor cell count. The number of photoreceptors in the control and cDKO were quantified by averaging the total number of cells in a 200 $\mu \mathrm{m}$ region taken from the central and peripheral retina on three different retinal sections per animal. Statistical comparisons were done using Student's $t$ test.

IS quantification. Cngal localization in the IS in control and $\mathrm{cDKO}$ was quantified by averaging the total number of IS displaying Cnga1 labeling on three different retinal sections per animal. IS was identified using morphology. Statistical comparisons were done using Student's $t$ test.

Fluorescence intensity measurements. Intensity measurements were obtained using the Volocity software (PerkinElmer). Auto-threshold adjustment was applied to the image before the measurement. The experiment was repeated twice and 20-40 cells were analyzed for each condition in every experiment.

\section{Viral vectors and intraocular injections}

The titer of the AAV vectors used was $6.36 \times 10^{13} \mathrm{pfu} / \mathrm{ml}$ and the serotype was AAV5. The procedures for construction and purification of 


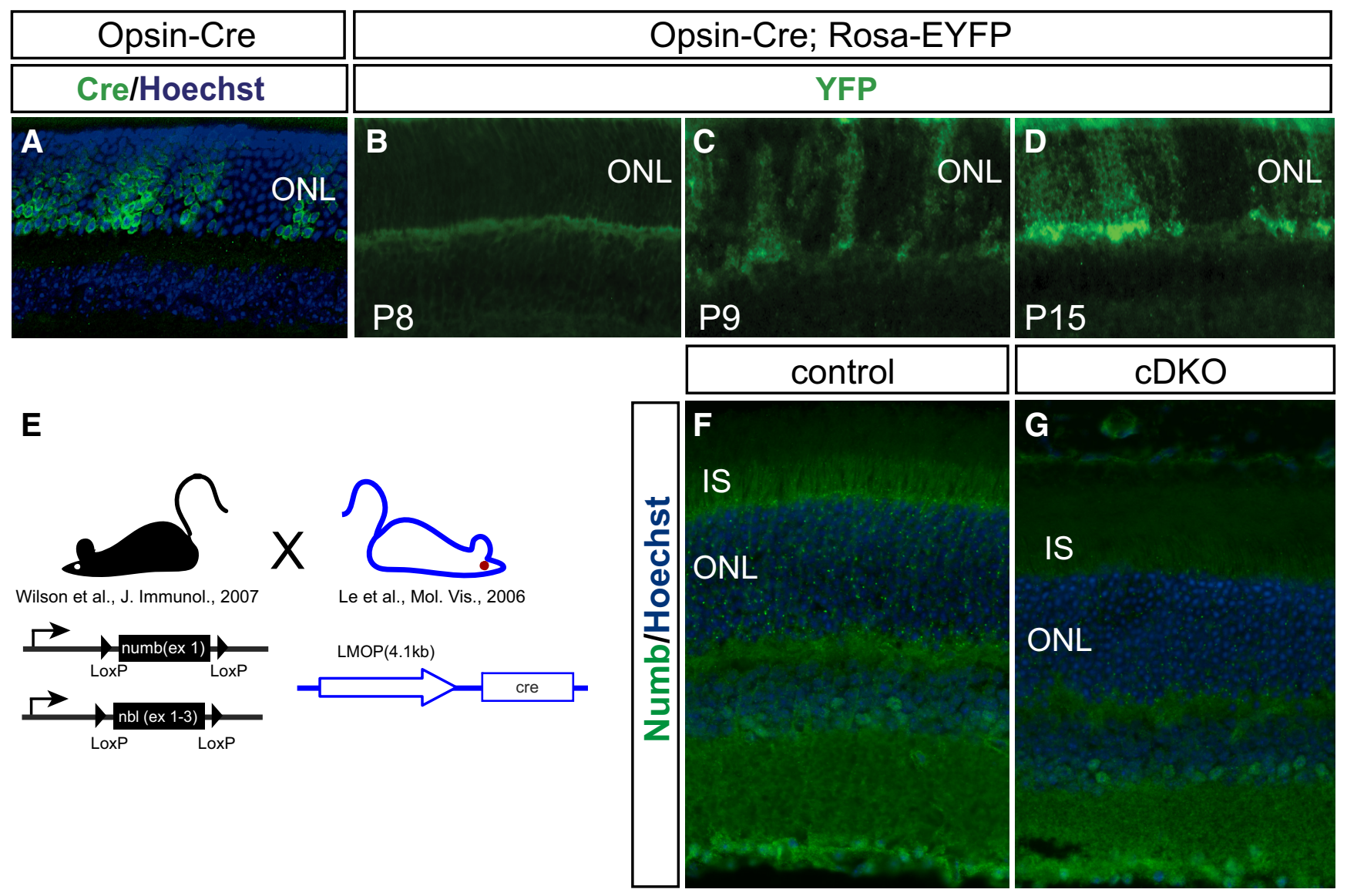

Figure 2. Conditional inactivation of $\mathrm{Numb} / \mathrm{NbL}$ in photoreceptors. $A$, Immunostaining for Cre on retinal sections of Opsin-Cre mouse at P60. (re (green) is expressed only in photoreceptor cells located in the ONL. Note the mosaic expression pattern of Cre in the photoreceptor layer. $\boldsymbol{B}-\boldsymbol{D}$, Recombination efficiency in the Opsin-Cre mouse. Immunostaining for YFP on mouse retinal sections of a F1 double-transgenic Opsin-Cre; R26R-EYFP at different stages, as indicated. Recombination, as indicated by YFP expression (green), is mosaic and starts at P9, but is more robust by P15. $\boldsymbol{E}$, A diagram illustrating the breeding scheme to generate Numb/NbL CDKO. $F, G$, Immunostaining for Numb on retinal sections from cDK0 at P60. Numb (green) expression is decreased in the cDK0 in the apical IS, indicating efficient gene inactivation. For illustration purposes, an area with complete loss of Numb signal was selected, but other areas of the same retina had some Numb staining remaining, as expected due to mosaicism of Cre activity shown in $\boldsymbol{A}-\boldsymbol{D}$. Sections were counterstained with Hoechst (blue) to reveal nuclei in $\boldsymbol{A}, \boldsymbol{F}$, and $\mathbf{G}$.

adenoviral vectors and intraocular injections was described previously (Flannery et al., 1997). The volume of the injection was maintained between 0.5 and $1 \mu \mathrm{l}$. Animals were injected with AAV-Cre-GFP into one eye and received a control injection of vehicle or AAV-GFP into the contralateral eye.

Protein extraction, immunoblotting, and immunoprecipitation Cells were harvested, and lysed in a NP-40 buffer: $50 \mathrm{~mm}$ TRIS, $\mathrm{pH}$ 8.0, $150 \mathrm{~mm} \mathrm{NaCl}, 1.0 \%$ NP-40 with Complete Protease Inhibitor Cocktail (Roche). For immunoblotting, $100 \mu \mathrm{g}$ of protein samples were separated by electrophoresis on a 10\% SDS-PAGE gels and then transferred onto PVDF membranes (Millipore). The membranes were blocked with 5\% milk in TBST ( $\mathrm{pH} 8.0,0.1 \%$ Triton). Immunoblotting with the primary antibody (Table 1) was performed at $4^{\circ} \mathrm{C}$ overnight in $0.5 \%$ dry milk in TBST. The primary antibody was detected with an HRP-conjugated goat anti-rabbit (1: 10,000; Jackson Immunoresearch) in 0.5\% dry milk in TBST. Detection of bound antibodies was visualized with the ECL kit (GE Life Science).

For immunoprecipitation (IP), Dynabeads Magnetic Beads (Dynabeads Protein G, Invitrogen) were used according to manufacturer's specification. Briefly, $40 \mu \mathrm{l}$ of beads were incubated with primary antibody (Table 1 ) for $1 \mathrm{~h}$ at $4^{\circ} \mathrm{C} .1 \mathrm{mg}$ of cell lysate was incubated with the bead-antibody mixture in Iph Buffer (50 mu Tris ph 8.0, $150 \mathrm{~mm} \mathrm{Nacl}, 5$ mM EDTA, $0.1 \%$ NP-40) overnight at $4^{\circ} \mathrm{C}$. The beads were separated using a magnet (MagnaBind, Pierce) and washed in Iph Buffer. The beads were then boiled in $2 \times$ Laemmli buffer at $95^{\circ} \mathrm{C}$ for $10 \mathrm{~min}$ and the supernatant was used for immunoblotting as described above.

\section{Results}

Numb and $\mathrm{NbL}$ are expressed in photoreceptors

We found that both numb and $n b l$ mRNA are expressed in all cell layers of the adult retina, but particularly enriched in the photoreceptor layer (Fig. $1 B, C$ ). In photoreceptors, the Numb protein was strikingly polarized in a subdomain of the sensory cilium, which matched the IS marker $\mathrm{Na}^{+} / \mathrm{K}^{+}$ATPase, but did not overlap with the OS marker Rom-1 (Fig. 1D-I). Consistently, immuno-EM revealed no signal for Numb in the OS, but strong localization in the IS (Fig. $1 J$ ). In vivo electroporation of a fluorescently tagged version of Numb (Numb::Venus), which was previously reported to localize like endogenous Numb (Kechad et al., 2012), was also concentrated in the IS and excluded from the cell body and OS, unlike the control Venus protein (Fig. $1 K-L)$, further supporting the immunostaining data. To determine whether Numb is expressed in cone photoreceptors, we stained $n r l$ KO retinas, which contain only cones (Mears et al., 2001), thereby facilitating the interpretation of the staining. Interestingly, we did not detect any Numb labeling in cone IS/OS area (Fig. $1 M, N$ ), suggesting that Numb is not expressed in cones. Together, these results indicate that both Numb and $\mathrm{NbL}$ are expressed in rod photoreceptors and that Numb is highly polarized in the IS, where protein synthesis takes place. 

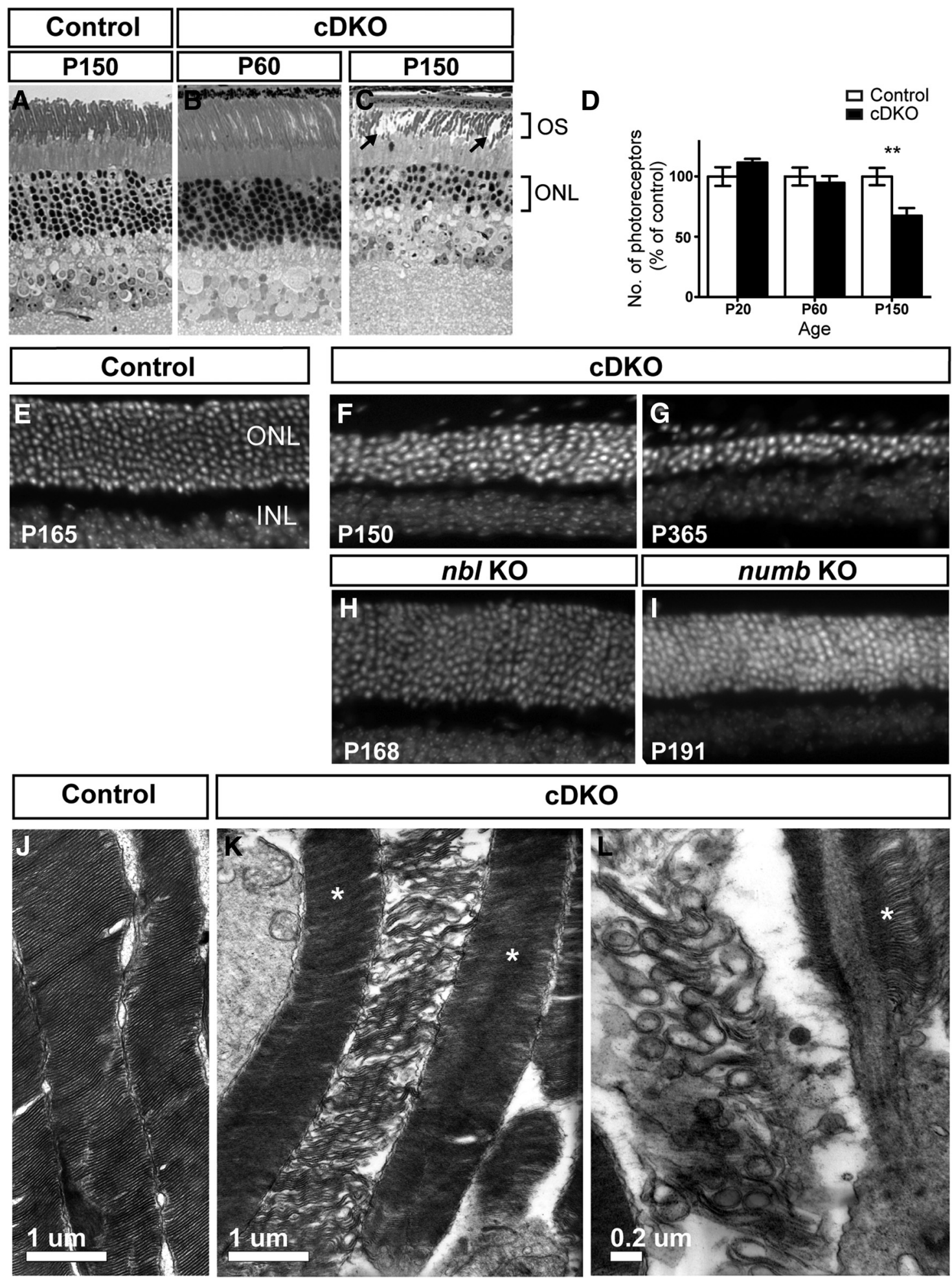

Figure 3. Numb/NbL function is required for rod photoreceptor cell survival. $\boldsymbol{A}-\boldsymbol{C}$, Toluidine blue staining of retinal sections from a $(\mathrm{re}-\mathrm{negative}(\mathrm{Control}) \mathrm{mouse}$ at $\mathrm{P} 150(\boldsymbol{A})$ and $\mathrm{CDKO}$ at P60 (B) and P150 (C). The CDK0 retina appears normal at P60, whereas photoreceptors are degenerating at P150, as shown by the thinning of the $0 \mathrm{NL}$, loss of columnar organization of nuclei and degeneration of the $0 S$ ( $\boldsymbol{C}$, arrows). $\boldsymbol{D}$, Quantification (mean \pm SEM) of the number of photoreceptors in the $C D K 0$ and control retinas at P20, P60, and P150 ( $n=5$ animals for each time; ${ }^{* *} p=0.0093$; Student's $t$ test). $\boldsymbol{E}-\boldsymbol{G}$, Retinal sections from control $(\boldsymbol{E}), \mathrm{CDKO}(\boldsymbol{F}, \boldsymbol{G})$, single $n b / \mathrm{KO}(\boldsymbol{H})$, or numb (I) K0, stained with Hoechst to visualize nuclei at different postnatal days, as indicated. In the CDK0, photoreceptor degeneration is clearly detected by P150 (F), but progressively worsens with age and is almost complete by 1 year $(\boldsymbol{G})$, when only two to three rows of photoreceptors are left in the $0 \mathrm{NL}$. Single KOs do not show any signs of photoreceptor degeneration. $J-L$, Electron micrographs of control and cDKO photoreceptor OS. Control OSs $(J)$ show regular stacking of disks enclosed within a plasma membrane, but CDKO OSs appear disorganized $(\boldsymbol{K}, \boldsymbol{L})$. Note that not all 0Ss are degenerating at this age (asterisks), most likely reflecting the mosaicism of numb/nb/ deletion. 


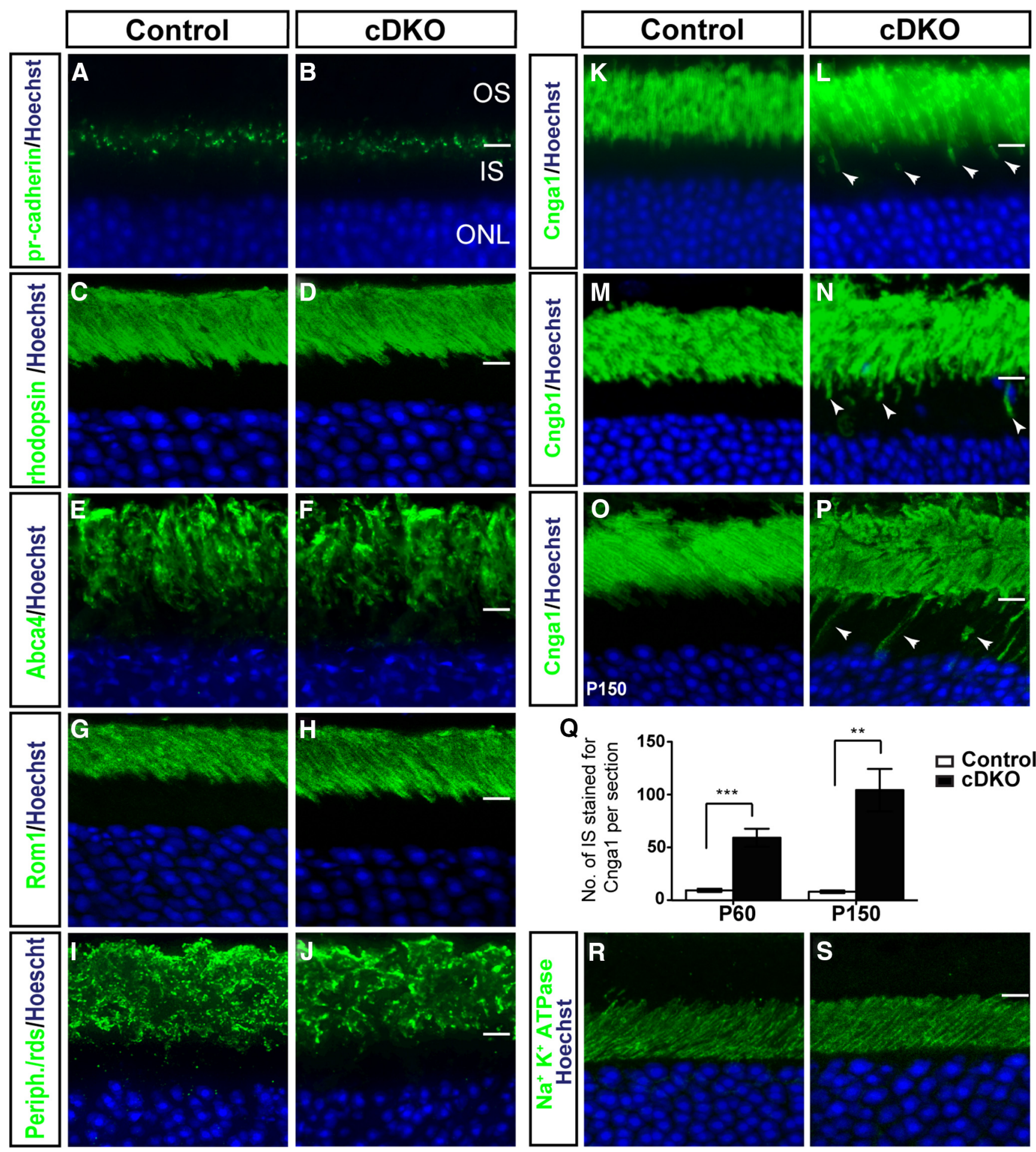

Figure 4. Numb/NbL function is required for the exclusive localization of Cng channels in rod photoreceptor outer segments. $A-P$, Immunostaining of retinal sections from control and cDKO mouse at P60 $(\boldsymbol{A}-\boldsymbol{N})$ and P150 $(\boldsymbol{O}, \boldsymbol{P})$ for photoreceptor-specific cadherin $(\boldsymbol{A}, \boldsymbol{B})$, or various 0 S markers, as indicated. Although all 0S disk membrane proteins studied (rhodopsin, Abca4, Rom1, and Peripherin-rds) localize normally in cDK0, Cnga1 and (ngb1 are abnormally detected in the IS (arrowheads in $L, N, P$ ), in addition to their normal localization in the $0 S$. $Q$, Quantification of the number of IS with Cnga 1 labeling in the IS per retinal section in CDKO compared with wild-type controls at P60 and P150 (mean \pm SEM; $n=5$ animals; ${ }^{* * *} p=0.0007,{ }^{* *} p=0.0014$, Student's $t$ test). $\boldsymbol{R}$, $\boldsymbol{S}$, Immunostaining of P60 retinal sections from control (R) and CDKO (S) mouse for $\mathrm{Na}^{+} / \mathrm{K}^{+}$ATPase. All sections were counterstained with Hoechst (blue) to reveal nuclei.

$\mathrm{Numb} / \mathrm{NbL}$ function is required for rod photoreceptor cell survival

As Numb/NbL function is essential for embryonic development (Zhong et al., 2000; Zilian et al., 2001; Petersen et al., 2002) and normal cell fate decisions in the developing retina (Kechad et al., 2012), we generated a rod photoreceptor-specific knock-out mouse using the Opsin-Cre mouse line (Le et al., 2006). As expected, this line produced specific, albeit mosaic, recombination in rod photoreceptors from as early as P9 (Fig. 2A-D). We then crossed the Opsin-Cre mouse with a line carrying floxed alleles for both numb and $n b l$ (Wilson et al., 2007) to generate conditional double knock-outs (cDKO). As expected, Numb immuno- 

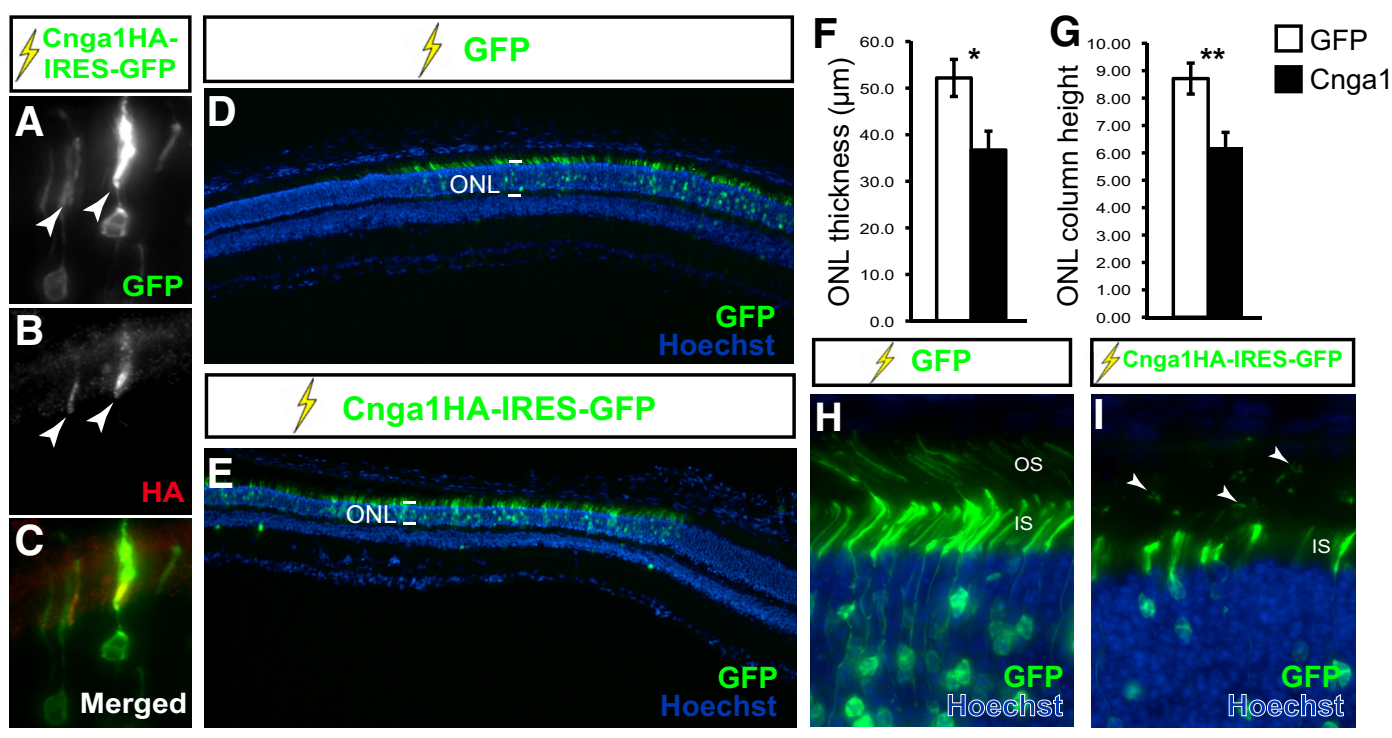

Figure 5. Overexpression of Cnga1 in wild-type photoreceptors induces degeneration. $\boldsymbol{A}-\boldsymbol{C}$, In vivo electroporation (lightning sign) of photoreceptors with a construct expressing both an HA-tagged version of mouse Cnga1 (Cnga1HA) and GFP from an internal ribosome entry site (IRES), stained for HA. Transfected photoreceptors expressing GFP ( $A$ ) show accumulation of Cnga1HA in the IS, as seen by HA staining $(\boldsymbol{B})$. D, $\boldsymbol{E}$, A low-magnification image of a region of the retina transfected with GFP $(\boldsymbol{D})$ or with $(n g a 1 H A-I R E S-G F P(\boldsymbol{E})$ constructs 3 weeks after electroporation. The GFP staining identifies transfected cells. The thickness of the $0 N L$, which contains photoreceptors, is much reduced in the (nga1-transfected regions (compared bracketed area in $\boldsymbol{D}$ and $\boldsymbol{E}$ ). $\boldsymbol{F}, \boldsymbol{G}$, Quantification of the $0 N L$ thickness in GFP- or Cnga1-transfected areas expressed both in $\mu \mathrm{m}(\boldsymbol{F} ; 0 \mathrm{NL}$ thickness) and as number of rows of photoreceptor nuclei (G; ONL column height). Both methods show significant reduction of ONL thickness after overexpression of Cnga1 (mean \pm SEM; ${ }^{*} p=0.04,{ }^{* *} p=0.01$, Student's $t$ test; $n=4$ GFP and 5 Cnga1-transfected retinas). High magnification view of photoreceptors 3 weeks after electroporation with GFP $(\boldsymbol{H})$ or (nga1HA-IRES-GFP $(\boldsymbol{I})$ constructs in vivo. Cnga1-expressing photoreceptors show fragmented 0S (arrowheads), a sign of degeneration.

staining in $\mathrm{CDKO}$ photoreceptors was drastically reduced (Fig. $2 E-G$ ), thereby confirming both the successful generation of a $\mathrm{cDKO}$ and the specificity of the antibody.

In $\mathrm{CDKO}$, retinal histology appeared normal within the first 2 months, but disorganized OS and a thinner photoreceptor layer was clearly detected by 5 months of age (Fig. $3 A-D$ ). The photoreceptor degeneration was progressive and almost complete by 12 months (Fig. $3 E-G$ ). In contrast, single knock-outs for either numb or $n b l$ had no signs of photoreceptor degeneration, even in animals older than 5 months (Fig. $3 H, I$ ), suggesting functional redundancy, as previously reported in other nervous tissues (Petersen et al., 2002, 2004). Closer examination of the cDKO OS by electron microscopy showed various defects ranging from loose stacking of membranes to completely disrupted OS structures (Fig. $3 J-L$ ). Thus, Numb/NbL function is essential for rod photoreceptor cell survival.

\section{$\mathrm{Numb} / \mathrm{NbL}$ function regulates polarized localization of rod cng channels to the $O S$}

How could Numb/NbL inactivation lead to progressive photoreceptor degeneration? Given that Numb/NbL control the maintenance of cadherin-based adhesions in neural progenitors (Rasin et al., 2007), we first asked whether photoreceptor-specific cadherin (pr-cadherin), which is essential for photoreceptor survival (Rattner et al., 2001), might be disrupted in cDKO. Immunostaining on control and cDKO retinal sections, however, did not reveal any obvious changes in the localization or expression level of pr-cadherin (Fig. $4 A, B$ ), arguing against this possibility.

As abnormal trafficking of OS proteins is known to eventually lead to photoreceptor cell death (Insinna and Besharse, 2008; Ramamurthy and Cayouette, 2009), we next wondered whether protein localization might be affected in $\mathrm{cDKO}$ photoreceptors. Because OS degeneration can indirectly lead to accumulation of OS proteins in the IS and cell body, we studied $\mathrm{P} 60$ retinas, a stage when degeneration is not yet detected in cDKO (Fig. $3 B, D$ ).
Whereas proteins normally found on the OS disk membrane, such as rhodopsin, Abca4, Rom-1, and Peripherin/rds localized normally (Fig. 4C-J), the OS plasma membrane proteins Cngal and Cngb 1 abnormally accumulated in the IS of CDKO photoreceptors, in addition to their normal localization in the OS (Fig. $4 K-N)$. This accumulation worsened with age and was more drastic by P150 (Fig. 4O-Q). We next wanted to determine whether other OS plasma membrane proteins, such as the $\mathrm{Na}^{+}$/ $\mathrm{Ca}^{2+} / \mathrm{K}^{+}$exchanger, were also mislocalized in cDKO photoreceptors, but this was unfortunately not possible due to the lack of reliable antibodies. Nonetheless, to determine whether any photoreceptor plasma membrane protein trafficking was disrupted, we studied the localization of the $\mathrm{Na}^{+} / \mathrm{K}^{+}$ATPase, which localizes specifically on the IS plasma membrane, but found no change in cDKO photoreceptors (Fig. $4 R, S$ ). Together, these results indicate that $\mathrm{Numb} / \mathrm{NbL}$ function is required to prevent targeting of Cng channels to the IS plasma membrane. Since Cngal and Cngb1 are still normally localized in the OS of $\mathrm{cDKO}$, even in photoreceptors showing accumulation in the IS, these results argue against an essential role for Numb in the transport of Cng channels to the OS, and instead point to a role in sorting for the exclusive delivery to the OS plasma membrane.

Because accumulation of Cng channels in the IS is observed before we detect any photoreceptor degeneration in $\mathrm{CDKO}$, we reasoned that mislocalization of Cng channels might actually induce photoreceptor cell death. To test this possibility, we overexpressed Cngal in wild-type photoreceptors to produce artificial accumulation in the IS, therefore mimicking the CDKO phenotype. To do this, we electroporated retinas in vivo with a construct encoding an HA-tagged version of Cngal, as well as GFP, from an internal ribosome entry site (Cnga1HA-IRES-GFP), and then studied the effect of Cngal overexpression on photoreceptor survival 3 weeks later. As expected, overexpression of Cngal led to accumulation in the IS, as seen in GFP-positive transfected cells 
A
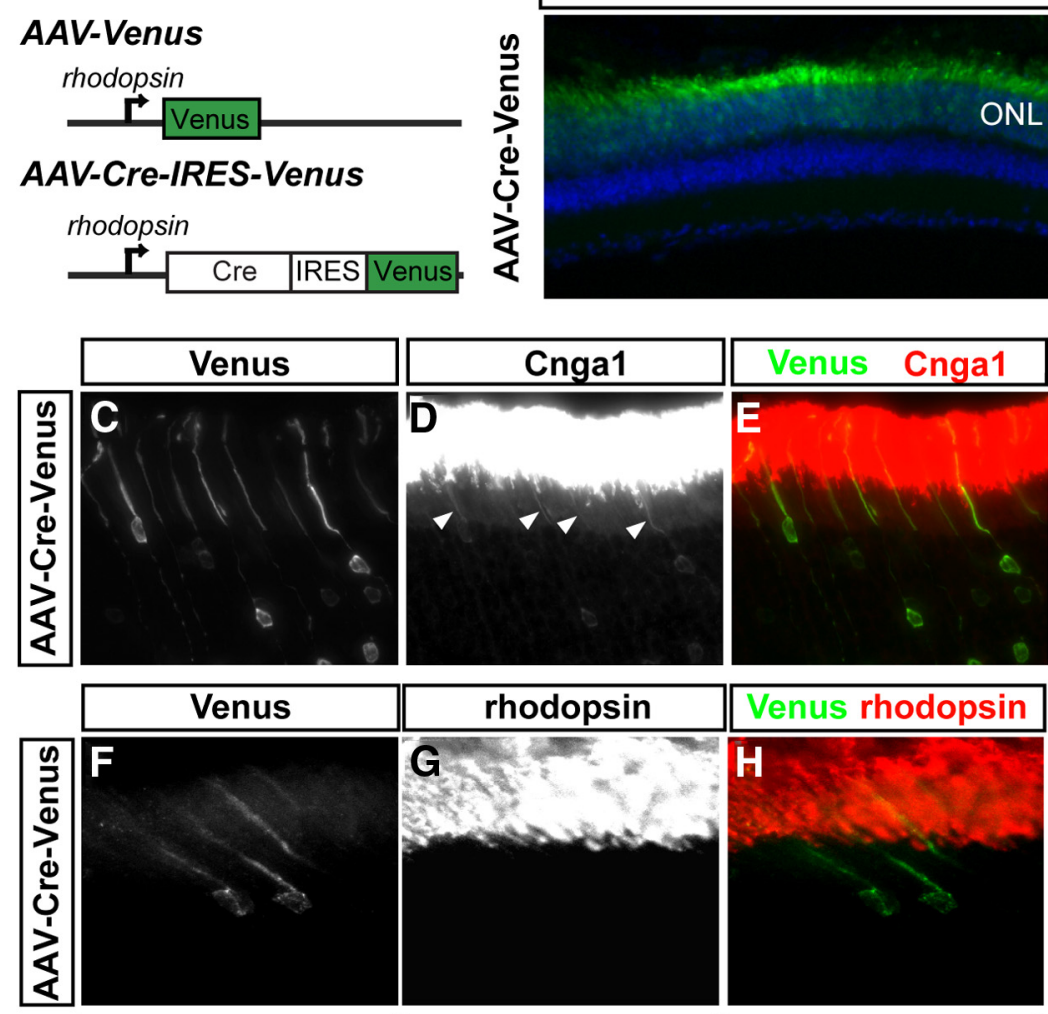

Venus rhodopsin
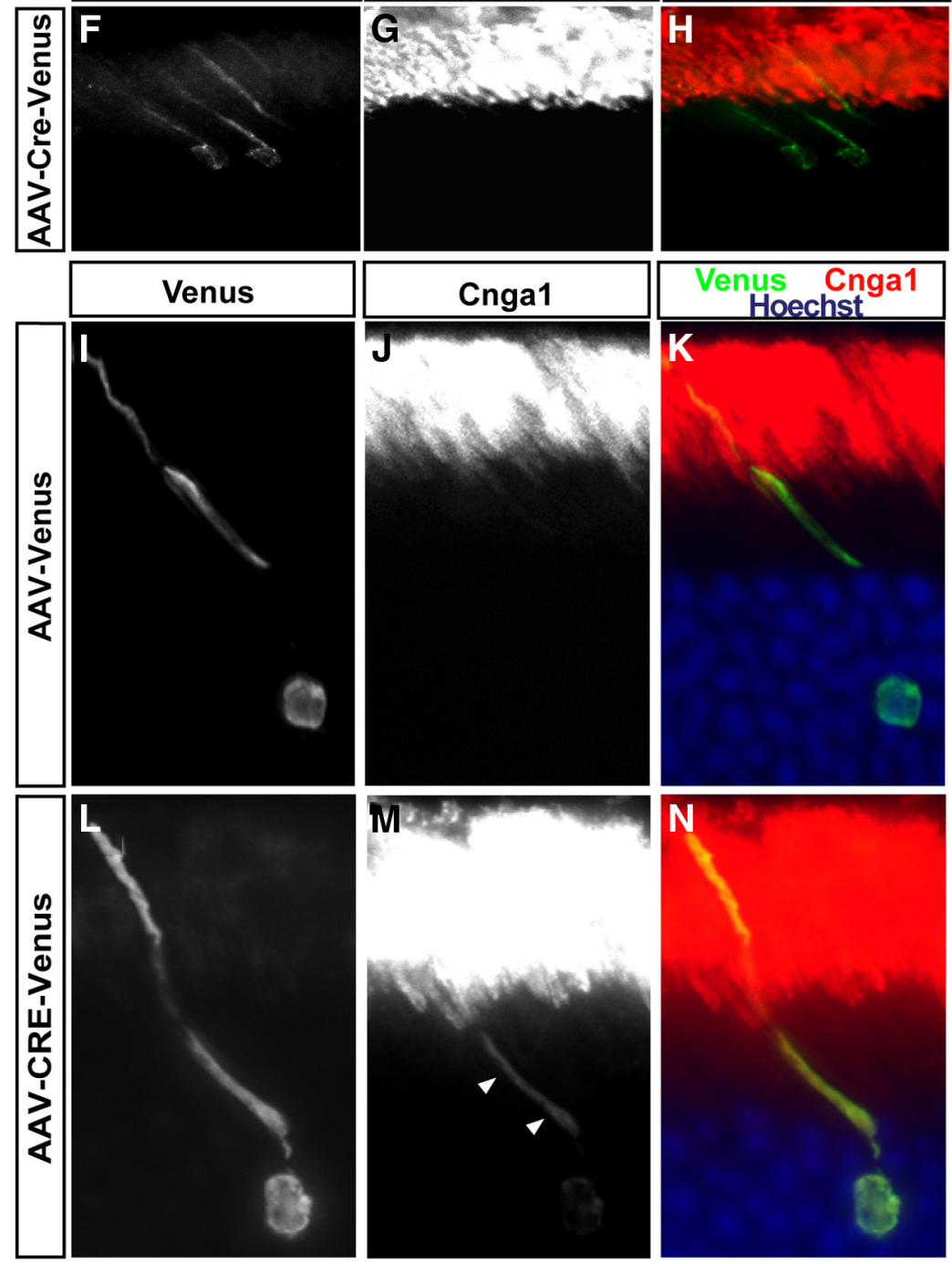

Figure 6. Numb/NbL function is required cell autonomously for Cnga1 trafficking. $\boldsymbol{A}$, Schematic representation of the AAV vectors. The $4.1 \mathrm{~kb}$ mouse rhodopsin promoter was used to drive Venus alone, or Cre recombinase and Venus using an internal ribosome entry site (IRES). $\boldsymbol{B}-\boldsymbol{N}$, Sections of Numb/Nbl flox/flox mouse retina infected with AAV-Venus or AAV-Cre-Venus and immunostained for Venus, Cnga1, and rhodopsin, as indicated. The AAV vectors were injected subretinally at P23 and the retina analyzed 3 weeks later. The AAV vectors specifically infected photoreceptor cells, as seen by specific Venus expression in the 0NL ( $\boldsymbol{B}$ stained for HA (Fig. 5A-C). Strikingly, Cngal-transfected areas showed a significant reduction in photoreceptor cell layer thickness compared with GFP-transfected controls (Fig. 5D-G). Interestingly, Cnga1overexpressing photoreceptors that were still present 3 weeks after electroporation had abnormal morphology with reduced OS length and fragments of degenerating OS membranes accumulating in the subretinal space (Fig. $5 H, I$ ), similar to what we observe in the $\mathrm{CDKO}$ retina in vivo (see Fig. $3 C, I, J)$. Together, these results suggest that accumulation of Cngal in the inner segment is detrimental to photoreceptor survival and eventually leads to cell death.

Numb/NbL function cellautonomously to regulate rod cng channel localization to the OS Although the above results implicate $\mathrm{Numb} / \mathrm{NbL}$ function in Cng channel localization, it remained possible that (1) Cng channel mislocalization occurs only in photoreceptors with degenerating OS that could have gone unnoticed in a section containing many thousands of photoreceptors, (2) Numb inactivation from P9 using the Opsin-Cre driver affect OS development in some ways that later lead to abnormal trafficking of the channels, and (3) loss of Numb in a large proportion of photoreceptors cause changes in cellcell interactions that indirectly affect Cng channel trafficking. To address these issues, we generated adeno-associated viral (AAV) vectors expressing either Venus alone (AAV-Venus) or Cre and Venus (AAV-Cre-IRES-Venus) under the regulation of the rod-specific opsin promoter (Fig. 6A). These vectors allowed us to visualize individual infected cell morphology using the Venus reporter and to control the timing of gene inactivation by introducing the virus into floxed mice at any given stage. To avoid effects of Numb/ $\mathrm{NbL}$ inactivation on the development of OS, the AAV vectors were injected into the subretinal space of numb/nbl floxed mice at P21, a stage when the OS are fully developed, and the retinas were collected

green). AAV-Cre-Venus-infected photoreceptors display a normal morphology, as visualized by Venus expression. Cnga1 (red) labels the outer segments, but also some IS in AAV-CreVenus-infected photoreceptors (arrowheads in $\boldsymbol{D}$ and $\boldsymbol{M}$ ), as observed in the CDKO in vivo. Noninfected or control-infected photoreceptors do not show accumulation of Cnga1 in the IS $(D, J)$. AAV-Cre-Venus-infected photoreceptors do not show any mislocalization of rhodopsin $(\boldsymbol{F}-\boldsymbol{H})$. Sections were counterstained with Hoechst (blue) to reveal nuclei in $\boldsymbol{B}, \boldsymbol{K}$, and $\boldsymbol{N}$. 


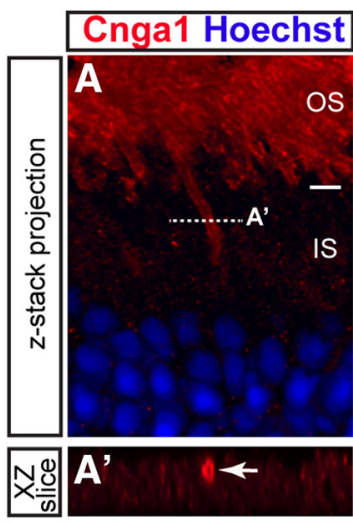

F
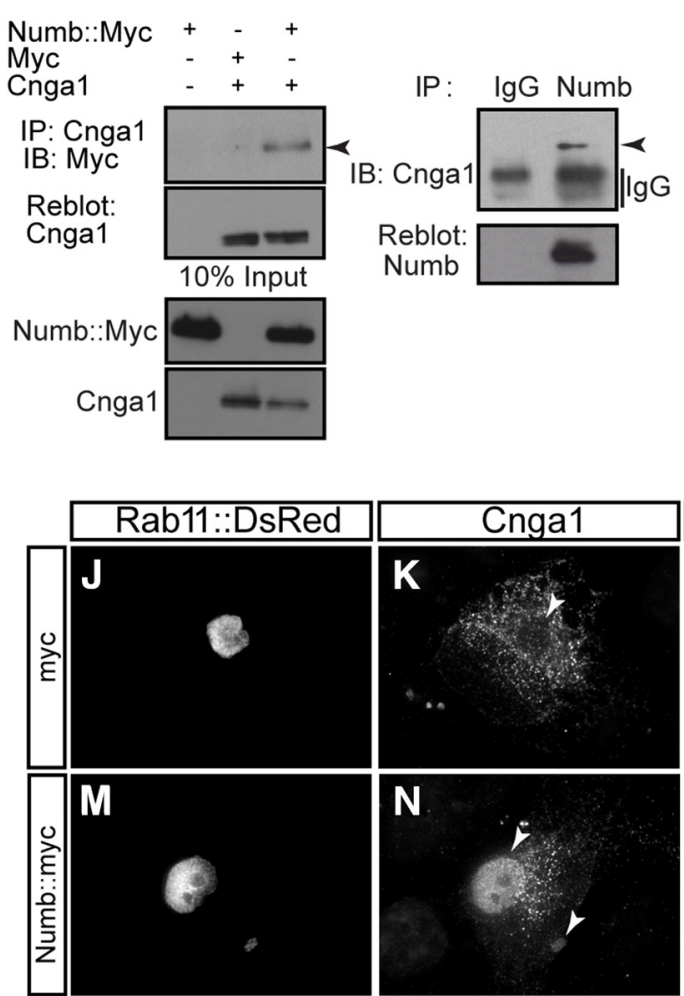

R

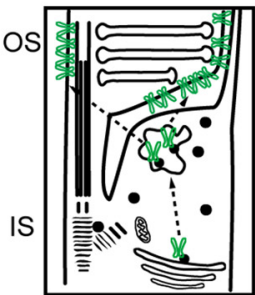

wildtype
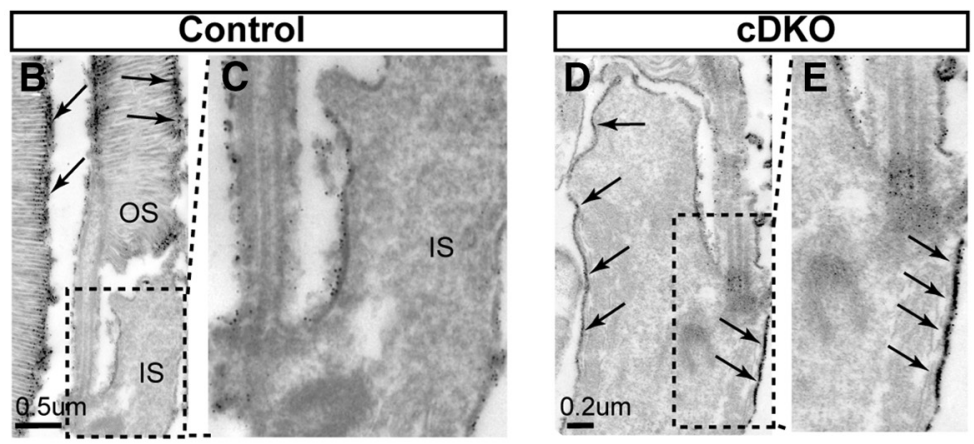

H

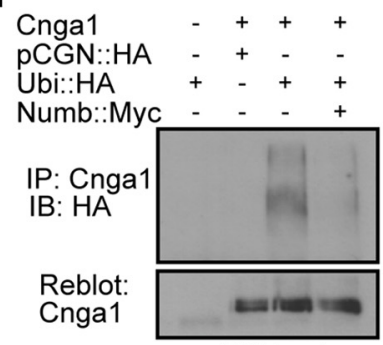

Reblot:

Cngb1
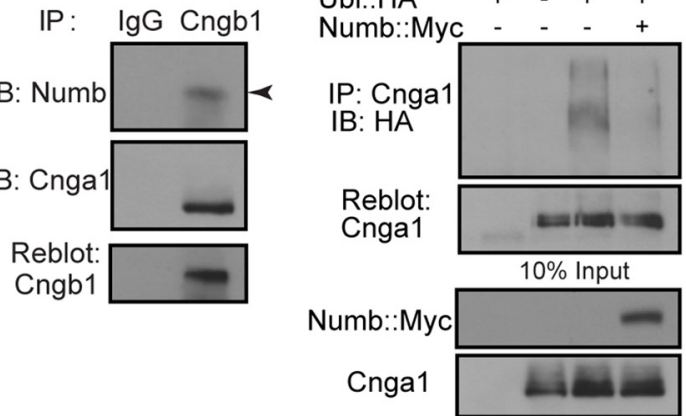

$P$

Q
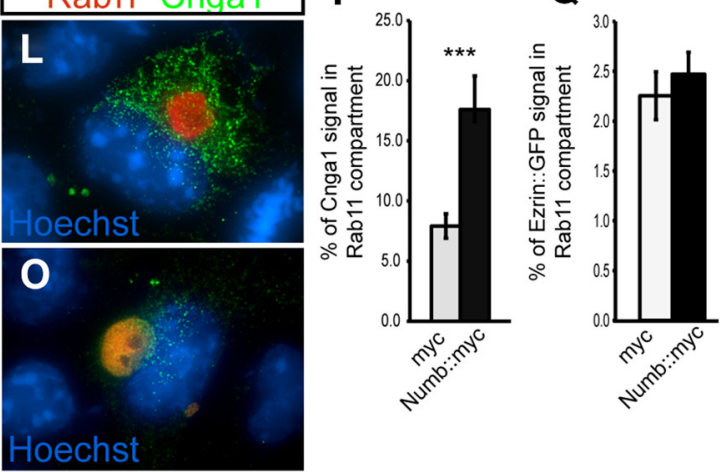

Figure 7. Numb interacts with Cng channel subunits and promotes trafficking of Cnga1 to the recycling endosome. $A$, Confocal $z$-stack projection of a cDKO retinal section at $P 60$ immunostained for Cnga1 (red) and Hoechst (blue). The dotted line indicates the XZ slice view shown in $\boldsymbol{A}^{\prime}$. Cnga1 accumulates on the outer edge of the IS (arrow). $\boldsymbol{B}-\boldsymbol{E}$, Electron micrographs of control ( $\boldsymbol{B}, \boldsymbol{C}$ ) and CDKO $(\boldsymbol{D}, \boldsymbol{E})$ photoreceptors immunostained for $C$ nga 1 at P60. DAB precipitates were silver intensified and appear as black dots on the image. The boxed areas in $\boldsymbol{B}$ and $\boldsymbol{D}$ indicate the magnified views shown in $\boldsymbol{C}$ and $\boldsymbol{E}$. Cnga1 labeling is indicated by arrows. $\boldsymbol{F}$, Coimmunoprecipitation of Cnga1 and Numb in HEK293 cells. $\boldsymbol{G}$, Coimmunoprecipitation of Cnga1 and Numb in vivo at P60. $\boldsymbol{H}$ Coimmunoprecipitation of Numb and Cngb1 in vivo at P60. I, Pull down of Cnga1 with Ubiquitin-HA (Ubi::HA) in HEK293 cells, in presence of exogenous Numb (Numb::Myc) or not. IB, Immunoblotting. J-0, Cos-7 cells cotransfected with Rab11::DsRed and mouse Cnga1, in the presence of exogenous Numb (Numb::myc) or a control empty construct (myc). Cnga1 was detected by immunostaining. The amount of (nga1 in the recycling endosome (arrowheads) is increased upon Numb overexpression. $\boldsymbol{P}$, Fluorescence intensity measurements of the percentage (\%) of (nga1 signal localized in the Rab11 compartment over the total Cnga1 signal in control transfected (myc) and Numb overexpressing (Numb::myc) Cos-7 cells (mean \pm SEM; myc: $n=30$ cells; Numb::myc: $n=28$ cells; ${ }^{* * *} p=0.002$, Student's $t$ test). Q, Fluorescence intensity measurements of the percentage (\%) of Ezrin::GFP signal localized in the Rab11 compartment in control transfected (myc) and Numb overexpressing (Numb::myc) Cos-7 cells (mean \pm SEM; myc: $n=17$ cells; Numb::myc: $n=20$ cells; ${ }^{* * *} p=0.52$, Student's $t$ test). $\boldsymbol{R}$, A model of Numb/NbL function in photoreceptor cilia. In wild-type photoreceptors (left), Numb interacts with the Cng channels post-Golgi and promotes their trafficking to the recycling endosome, where they are sorted for specific delivery to the 0 S plasma membrane. In the absence of Numb (right), the Cng channel is not trafficked to the recycling endosome and cannot be sorted, such that it ends up localizing to both the IS and OS plasma membrane. 
and analyzed 2-3 weeks later. As expected, the rhodopsin promoter achieved highly specific photoreceptor expression (Fig. $6 B$ ). Interestingly, infection of numb/nbl floxed photoreceptors with AAV-Cre-IRES-Venus mimicked the phenotype observed in the cDKO mouse retina in vivo and led to clear accumulation of Cngal in the IS (Fig. $6 C-E$ ), whereas rhodopsin localization was not altered (Fig. $6 \mathrm{~F}-\mathrm{H}$ ). Remarkably, AAV-Cre appeared much more efficient than the Opsin-Cre cDKO line to inactivate $\mathrm{Numb} / \mathrm{NbL}$, as the large majority of infected photoreceptors (GFP-positive) showed accumulation of Cngal in the IS (74.3 \pm $2.0 \%, n=112$ cells from 4 different animals), compared with only 50-100 photoreceptors per retina section showing Cngal in the IS in the cDKO (Fig. 4Q). Importantly, the OS was clearly visualized in cells showing accumulation of Cngal in the IS and their morphology, as visualized by Venus expression, was indistinguishable from that of controls (Fig. 6C-E). Additionally, infection of wild-type photoreceptors with the same AAV-CreIRES-Venus vector did not have any effect on photoreceptor morphology or Cngal trafficking (data not shown), excluding the possibility that the injection procedure or expression of Cre indirectly leads to mislocalization of Cngal. Accumulation of Cngal in the IS was also readily observed in isolated Creexpressing photoreceptors, whereas Venus expression alone did not affect Cngal localization (Fig. $6 I-N$ ). Together, these results exclude OS developmental defects, degeneration, or noncell autonomous effects as possible explanations for the cDKO phenotypes, indicating that $\mathrm{Numb} / \mathrm{NbL}$ function cell-autonomously to regulate Cng channel localization.

\section{Cng channel accumulates on the IS plasma membrane of cDKO rod photoreceptors}

We next reasoned that identifying the exact location of Cng channel accumulation in cDKO IS would provide information about a potential mechanism for $\mathrm{Numb} / \mathrm{NbL}$ function. Detailed analysis of Cngal staining using three-dimensional confocal imaging showed concentrations around the edge of the IS, suggesting accumulation on the plasma membrane (Fig. $7 A, A^{\prime}$ ). To confirm this interpretation, we used immunoEM. Strong Cngal staining was observed along the OS plasma membrane in both wild-type and $\mathrm{CDKO}$ photoreceptors, (Fig. $7 B$ and data not shown), but Cngal signal was additionally found on the IS plasma membrane of $\mathrm{cDKO}$ photoreceptors (Fig. 7C-E). These results suggest that $\mathrm{Numb} / \mathrm{NbL}$ function is not required for the general delivery of Cngal to the plasma membrane, but instead that it is essential to restrict delivery to the OS plasma membrane and/or prevent accumulation on the IS membrane.

\section{Numb physically interacts with cng channel subunits and regulates Cngal trafficking to the recycling endosome}

Given that Numb is a well known endocytic adaptor protein that interacts with various cargo proteins to regulate their trafficking (Santolini et al., 2000; McGill and McGlade, 2003; McGill et al., 2009), we asked whether it could form a complex with Cng channels. Consistently, we found that Numb and Cngal coimmunoprecipitate when exogenously expressed in cell lines (Fig. 7F). To study these interactions in vivo, we performed coimmunoprecipitations from protein extracts of adult mouse retina. We found that Cngal was pulled-down with an antibody to Numb (Fig. $7 G$ ), and conversely, an antibody to Cngb1 was able to pull-down Numb (Fig. 7H), as well as Cnga 1, as previously reported (Hüttl et al., 2005). These results suggest that Numb forms a complex with Cngal and Cngb1 in vivo.

Because Numb was previously reported to interact with ubiquitin ligases (Juven-Gershon et al., 1998; Susini et al., 2001; Nie et al.,
2002) to regulate the degradation of various cargos (Qiu et al., 2000; McGill and McGlade, 2003; Di Marcotullio et al., 2006, 2011; McGill et al., 2009), we first hypothesized that it might promote the local removal of Cng channels from the IS plasma membrane by promoting their ubiquitination and degradation. To test this possibility, we cotransfected HEK293 cells with a HA-tagged ubiquitin (Ubi::HA) together with Cngal in the presence or absence of exogenous Numb, immunoprecipitated with Cngal, and probed the blots for HA. In contrast to what we predicted, however, we found that Numb expression actually decreased the levels of Ubi::HA that coimmunoprecipitated (Fig. 7I), suggesting that Numb reduces Cngal degradation, possibly promoting trafficking to another intracellular pathway.

Because the recycling endosome is known for its role as an intermediate sorting station for apical transport (Rodriguez-Boulan and Macara, 2014), we hypothesized that the presence of Numb might promote trafficking of Cng channels to the recycling endosome. To study the role of Numb on the trafficking of Cng channel, we cotransfected Cngal or the cytoplasmic peripheral membrane protein Ezrin::GFP as control, together with a fluorescent fusion construct for the recycling endosome (Rab11::DsRed), and either control empty vector (myc) or exogenous Numb (Numb::myc) in COS-7 cells. Interestingly, we found that although only a small fraction of Cngal localized to Rab11-positive compartments in myctransfected or nontransfected cells, we observed a significant increase in the amount of Cngal in the Rab11 compartments in Numb-overexpressing cells (Fig. 7J-P). In contrast, Numb overexpression did not affect the trafficking of Ezrin::GFP (Fig. 7Q). Interestingly, accumulation of Cngal in Rab11-positive endosomes was often accompanied by a general decrease of Cngal levels in the rest of the cell (Fig. 7M-O), suggesting a redirection of Cngal from other compartments to the recycling endosome in the presence of Numb. These results indicate that Numb regulates the trafficking of Cngal to the recycling endosome and, together with our in vivo findings, suggest that this is an important step in preventing Cng channels from being targeted to the IS plasma membrane, and for the specific and exclusive delivery to the OS plasma membrane.

\section{Discussion}

Abnormal trafficking of ciliary proteins is a major cause of a class of human diseases known as ciliopathies, but the molecular mechanisms regulating polarized protein transport to cilia remain largely unknown. In this study, we used mouse genetics to uncover a novel function for Numb in the polarized delivery of ion channels to photoreceptor cilia. These results could have important consequences in our understanding of some retinal degenerative diseases and other ciliopathies. We discuss these implications below.

A particularly important finding in this study is the progressive photoreceptor degeneration observed in cDKO retinas, which identifies Numb as a key regulator of photoreceptor cell homeostasis and survival. While the exact cause of photoreceptor cell death remains unclear, accumulation of Cng channels on the IS plasma membrane might cause overactivation of the channel, which could raise intracellular $\mathrm{Ca}^{2+}$ concentrations and lead to cell death (Fox et al.,1999; Vallazza-Deschamps et al., 2005). Future investigations using $\mathrm{Ca}^{2+}$ imaging in $\mathrm{cDKO}$ photoreceptors might help address this question directly. Nonetheless, our finding that overexpression of Cngal in wild-type photoreceptors induces degeneration is consistent with the possibility that accumulation of Cngal on the IS plasma membrane in Numb/NbL cDKO is detrimental to photoreceptor survival. Photoreceptor degeneration in the $\mathrm{CDKO}$ retina might also be indirect. Indeed, a number of reports have linked intracellular accumulation of rhodopsin and the consequent production of oxidative 
damage with retinal degenerations (Nir and Papermaster, 1989; Agarwal et al., 1990; Nir et al., 1990; Chinchore et al., 2009). Because rhodopsin (and many other disk membrane proteins) eventually accumulates in the IS of old Numb/NbL cDKO retinas ( $>$ P150; data not shown), most likely as a consequence of the degenerated OS, rhodopsin-mediated toxicity could be involved in the photoreceptor cell death of Numb/NbL cDKO.

Progressive photoreceptor cell loss, as observed in Numb/NbL cDKO, is a hallmark of several retinal degenerative diseases in humans (Li, 2001; Hartong et al., 2006). This raises the interesting possibility that mutations in $n u m b$ and/or $n b l$ might contribute to human diseases. Human NUMB maps to chromosome 14q24.3 and, interestingly, a $10-\mathrm{cM}$ region overlapping the Numb locus was linked to Leber congenital amaurosis (LCA), a severe form of autosomal recessive retinal degeneration (Stockton et al., 1998). Although SPATA7 was later identified as an LCA-causing gene in this region (Wang et al., 2009), it remains possible that unidentified mutations in NUMB contribute to LCA pathogenesis. Because Numb/ $\mathrm{NbL}$ are essential for embryonic development, it is unlikely that null mutants exist in humans. Nonetheless, point mutations might affect Numb interaction with various cargos or endocytic proteins, altering normal Numb function in photoreceptors. Alternatively, mutations in Cnga1, which have been associated with retinitis pigmentosa in humans (Dryja et al., 1995), might modify its normal interaction with Numb, thereby disrupting localization of the channel that would lead to retinal degeneration, as we observed in the cDKO mouse. It will therefore be important to investigate whether the mutated forms of the Cng channel identified in human patients normally interact with Numb or not, as this could provide a molecular basis for the pathogenesis of the disease.

In primary cilia, a membrane diffusion barrier between the ciliary and plasma membrane prevents intermixing of proteins localized in the two domains (Nachury et al., 2010). A similar diffusion barrier was proposed to exist in photoreceptors, at the base of the connecting cilium, which link the IS to the OS (Nachury et al., 2010). Given that Numb promotes maintenance of diffusion barriers in epithelial cells (Sato et al., 2011), it appears plausible that barrier disruption could cause Cng channels to diffuse back into the IS in Numb/NbL cDKO photoreceptors. The overall levels of Cng channels in the OS, however, appear unchanged in the $\mathrm{CDKO}$ and after AAV-mediated gene inactivation, whereas they would be expected to decrease if the channel was free to diffuse back into the IS. Additionally, the IS plasma membrane protein $\mathrm{Na}^{+} / \mathrm{K}^{+}$ATPase does not diffuse into the OS of $\mathrm{CDKO}$, as would be expected if a diffusion barrier was disrupted. Therefore, our data does not appear consistent with the possibility that Numb controls the integrity of diffusion barriers in photoreceptors.

Instead, our results favor a model in which Numb is acting as a key adaptor to regulate Cng channel trafficking and sorting. Our observation that Numb and the Cng channel subunits interact both in vitro and in vivo is consistent with this possibility. Because Numb localizes to the IS, and most of the Cng channels are found in the OS, it is likely that the interaction actually takes place transiently in the IS, along the trafficking route used by the Cng channel to the OS. Although we could not study the trafficking of Cng channels in photoreceptors due to technical difficulties, we provide evidence in a heterologous cell system that exogenous Numb overexpression promotes the delivery of Cnga1 to Rab11-positive recycling endosome. Interestingly, a recent study showed that rhodopsin also transits through the recycling endosome en route to the apical plasma membrane in polarized MDCK cells, and that Rab11 is required for the appropriate sorting of rhodopsin to the apical membrane (Thuenauer et al., 2014). Additionally, Rab11 is part of a "ciliary targeting module" that regulate rhodopsin transport to the OS (Deretic and Wang, 2012). Rhodopsin trafficking, however, appears normal at $\mathrm{P} 60$ in the Numb/NbL cDKO photoreceptors, like other OS disk membrane proteins that we studied, excluding a direct role for $\mathrm{Numb} / \mathrm{NbL}$ in disk membrane protein trafficking. Instead, our data suggest that Numb/NbL act as key regulators of OS plasma membrane protein sorting. Our observation that cone photoreceptors, which do not have an OS plasma membrane that is distinct from the disk membrane, do not stain for Numb is consistent with this possibility. In cDKO, the Cng channel is normally transported to the OS plasma membrane, but additionally accumulates on the IS plasma membrane. This observation indicates that Numb is required to prevent targeting of Cng channels to the IS, but not for its general delivery to the OS plasma membrane. We propose that Numb regulates the trafficking of Cng channels to the recycling endosome, where they can be properly sorted for specific delivery to the OS plasma membrane. In the absence of Numb, the Cng channels do not efficiently transit through the recycling endosome and cannot be sorted, such that they end up being delivered to the entire apical plasma membrane, comprising both the IS and OS (Fig. 7R). Whether Numb plays an active part in the sorting of Cng channels in the recycling endosome, or only promotes trafficking of the channel to the recycling endosome, will require future investigation.

In conclusion, we have identified a mechanism controlling the polarized delivery of Cng channels to the OS. Because OS disk membranes are normally trafficked in the absence of Numb, our results suggest that Numb may be specifically required for the sorting of proteins destined to the plasma membrane of OS. Considering that OS are specialized primary cilia, these results suggest that Numb might also be involved in regulating the trafficking proteins to other types of primary cilia.

\section{References}

Agarwal N, Nir I, Papermaster DS (1990) Opsin synthesis and mRNA levels in dystrophic retinas devoid of outer segments in retinal degeneration slow (rds) mice. J Neurosci 10:3275-3285. Medline

Chinchore Y, Mitra A, Dolph PJ (2009) Accumulation of rhodopsin in late endosomes triggers photoreceptor cell degeneration. PLoS Genet 5:e1000377. CrossRef Medline

Choudhury A, Dominguez M, Puri V, Sharma DK, Narita K, Wheatley CL, Marks DL, Pagano RE (2002) Rab proteins mediate Golgi transport of caveola-internalized glycosphingolipids and correct lipid trafficking in Niemann-Pick C cells. J Clin Invest 109:1541-1550. CrossRef Medline

Connell G, Bascom R, Molday L, Reid D, McInnes RR, Molday RS (1991) Photoreceptor peripherin is the normal product of the gene responsible for retinal degeneration in the rds mouse. Proc Natl Acad Sci U S A 88: 723-726. CrossRef Medline

Cook NJ, Molday LL, Reid D, Kaupp UB, Molday RS (1989) The cGMPgated channel of bovine rod photoreceptors is localized exclusively in the plasma-membrane. J Biol Chem 264:6996-6999. Medline

Deretic D, Wang J (2012) Molecular assemblies that control rhodopsin transport to the cilia. Vision Res 75:5-10. CrossRef Medline

Di Marcotullio L, Ferretti E, Greco A, De Smaele E, Po A, Sico MA, Alimandi M, Giannini G, Maroder M, Screpanti I, Gulino A (2006) Numb is a suppressor of hedgehog signalling and targets Glil for itch-dependent ubiquitination. Nat Cell Biol 8:1415-1423. CrossRef Medline

Di Marcotullio L, Greco A, Mazzà D, Canettieri G, Pietrosanti L, Infante P, Coni S, Moretti M, De Smaele E, Ferretti E, Screpanti I, Gulino A (2011) Numb activates the E3 ligase itch to control Glil function through a novel degradation signal. Oncogene 30:65-76. CrossRef Medline

Dryja TP, Finn JT, Peng YW, McGee TL, Berson EL, Yau KW (1995) Mutations in the gene encoding the alpha subunit of the rod cGMP-gated channel in autosomal recessive retinitis pigmentosa. Proc Natl Acad Sci U S A 92:10177-10181. CrossRef Medline

Fariss RN, Molday RS, Fisher SK, Matsumoto B (1997) Evidence from normal and degenerating photoreceptors that two outer segment integral membrane proteins have separate transport pathways. J Comp Neurol 387:148-156. CrossRef Medline 
Flannery JG, Zolotukhin S, Vaquero MI, LaVail MM, Muzyczka N, Hauswirth WW (1997) Efficient photoreceptor-targeted gene expression in vivo by recombinant adeno-associated virus. Proc Natl Acad Sci U S A 94:6916-6921. CrossRef Medline

Fox DA, Poblenz AT, He L (1999) Calcium overload triggers rod photoreceptor apoptotic cell death in chemical-induced and inherited retinal degenerations. Ann N Y Acad Sci 893:282-285. CrossRef Medline

Hartong DT, Berson EL, Dryja TP (2006) Retinitis pigmentosa. Lancet 368: 1795-1809. CrossRef Medline

Hicks D, Molday RS (1986) Differential immunogold dextran labeling of bovine and frog rod and cone cells using monoclonal-antibodies against bovine rhodopsin. Exp Eye Res 42:55-71. CrossRef Medline

Hüttl S, Michalakis S, Seeliger M, Luo DG, Acar N, Geiger H, Hudl K, Mader R, Haverkamp S, Moser M, Pfeifer A, Gerstner A, Yau KW, Biel M (2005) Impaired channel targeting and retinal degeneration in mice lacking the cyclic nucleotide-gated channel subunit CNGB1. J Neurosci 25:130-138. CrossRef Medline

Illing M, Molday LL, Molday RS (1997) The 220-kDa Rim protein of retinal rod outer segments is a member of the $\mathrm{ABC}$ transporter superfamily. J Biol Chem 272:10303-10310. CrossRef Medline

Insinna C, Besharse JC (2008) Intraflagellar transport and the sensory outer segment of vertebrate photoreceptors. Dev Dyn 237:1982-1992. CrossRef Medline

Juven-Gershon T, Shifman O, Unger T, Elkeles A, Haupt Y, Oren M (1998) The Mdm2 oncoprotein interacts with the cell fate regulator Numb. Mol Cell Biol 18:3974-3982. Medline

Kechad A, Jolicoeur C, Tufford A, Mattar P, Chow RW, Harris WA, Cayouette M (2012) Numb is required for the production of terminal asymmetric cell divisions in the developing mouse retina. J Neurosci 32:17197-17210. CrossRef Medline

Kizhatil K, Baker SA, Arshavsky VY, Bennett V (2009) Ankyrin-G promotes cyclic nucleotide-gated channel transport to rod photoreceptor sensory cilia. Science 323:1614-1617. CrossRef Medline

Le YZ, Zheng L, Zheng W, Ash JD, Agbaga MP, Zhu M, Anderson RE (2006) Mouse opsin promoter-directed Cre recombinase expression in transgenic mice. Mol Vis 12:389-398. Medline

Lee ES, Burnside B, Flannery JG (2006) Characterization of peripherin/rds and rom-1 transport in rod photoreceptors of transgenic and knockout animals. Invest Ophthalmol Vis Sci 47:2150-2160. CrossRef Medline

Li T (2001) Disease model: photoreceptor degenerations. Trends Mol Med 7:133-135. CrossRef Medline

Matsuda T, Cepko CL (2004) Electroporation and RNA interference in the rodent retina in vivo and in vitro. Proc Natl Acad Sci U S A 101:16-22. CrossRef Medline

McGill MA, McGlade CJ (2003) Mammalian numb proteins promote Notch1 receptor ubiquitination and degradation of the Notch1 intracellular domain. J Biol Chem 278:23196-23203. CrossRef Medline

McGill MA, Dho SE, Weinmaster G, McGlade CJ (2009) Numb regulates post-endocytic trafficking and degradation of Notch1. J Biol Chem 284: 26427-26438. CrossRef Medline

Mears AJ, Kondo M, Swain PK, Takada Y, Bush RA, Saunders TL, Sieving PA, Swaroop A (2001) $\mathrm{Nrl}$ is required for rod photoreceptor development. Nat Genet 29:447-452. CrossRef Medline

Moritz OL, Molday RS (1996) Molecular cloning, membrane topology, and localization of bovine rom-1 in rod and cone photoreceptor cells. Invest Ophthalmol Vis Sci 37:352-362. Medline

Nachury MV, Seeley ES, Jin H (2010) Trafficking to the ciliary membrane: how to get across the periciliary diffusion barrier? Annu Rev Cell Dev Biol 26:59-87. CrossRef Medline

Nie J, McGill MA, Dermer M, Dho SE, Wolting CD, McGlade CJ (2002) LNX functions as a RING type E3 ubiquitin ligase that targets the cell fate determinant Numb for ubiquitin-dependent degradation. EMBO J 21: 93-102. CrossRef Medline

Nir I, Papermaster DS (1989) Immunocytochemical localization of opsin in degenerating photoreceptors of RCS rats and $\mathrm{rd}$ and rds mice. Prog Clin Biol Res 314:251-264. Medline

Nir I, Agarwal N, Papermaster DS (1990) Opsin gene expression during early and late phases of retinal degeneration in rds mice. Exp Eye Res 51:257-267. CrossRef Medline

Papermaster DS (2002) The birth and death of photoreceptors: the Friedenwald lecture. Invest Ophthalmol Vis Sci 43:1300-1309. Medline

Petersen PH, Zou K, Hwang JK, Jan YN, Zhong W (2002) Progenitor cell maintenance requires numb and numblike during mouse neurogenesis. Nature 419:929-934. CrossRef Medline

Petersen PH, Zou K, Krauss S, Zhong W (2004) Continuing role for mouse Numb and Numbl in maintaining progenitor cells during cortical neurogenesis. Nat Neurosci 7:803-811. CrossRef Medline

Qiu L, Joazeiro C, Fang N, Wang HY, Elly C, Altman Y, Fang D, Hunter T, Liu YC (2000) Recognition and ubiquitination of Notch by itch, a hect-type E3 ubiquitin ligase. J Biol Chem 275:35734-35737. CrossRef Medline

Ramamurthy V, Cayouette M (2009) Development and disease of the photoreceptor cilium. Clin Genet 76:137-145. CrossRef Medline

Rasin MR, Gazula VR, Breunig JJ, Kwan KY, Johnson MB, Liu-Chen S, Li HS, Jan LY, Jan YN, Rakic P, Sestan N (2007) Numb and Numbl are required for maintenance of cadherin-based adhesion and polarity of neural progenitors. Nat Neurosci 10:819-827. CrossRef Medline

Rattner A, Smallwood PM, Williams J, Cooke C, Savchenko A, Lyubarsky A, Pugh EN, Nathans J (2001) A photoreceptor-specific cadherin is essential for the structural integrity of the outer segment and for photoreceptor survival. Neuron 32:775-786. CrossRef Medline

Rodriguez-Boulan E, Macara IG (2014) Organization and execution of the epithelial polarity programme. Nat Rev Mol Cell Biol 15:225-242. CrossRef Medline

Salcini AE, Confalonieri S, Doria M, Santolini E, Tassi E, Minenkova O, Cesareni G, Pelicci PG, Di Fiore PP (1997) Binding specificity and in vivo targets of the EH domain, a novel protein-protein interaction module. Genes Dev 11:2239-2249. CrossRef Medline

Santolini E, Puri C, Salcini AE, Gagliani MC, Pelicci PG, Tacchetti C, Di Fiore PP (2000) Numb is an endocytic protein. J Cell Biol 151:1345-1352. CrossRef Medline

Sato K, Watanabe T, Wang S, Kakeno M, Matsuzawa K, Matsui T, Yokoi K, Murase K, Sugiyama I, Ozawa M, Kaibuchi K (2011) Numb controls E-cadherin endocytosis through p120 catenin with aPKC. Mol Biol Cell 22:3103-3119. CrossRef Medline

Stockton DW, Lewis RA, Abboud EB, Al-Rajhi A, Jabak M, Anderson KL, Lupski JR (1998) A novel locus for Leber congenital amaurosis on chromosome 14q24. Hum Genet 103:328-333. CrossRef Medline

Sung CH, Chuang JZ (2010) The cell biology of vision. J Cell Biol 190:953963. CrossRef Medline

Susini L, Passer BJ, Amzallag-Elbaz N, Juven-Gershon T, Prieur S, Privat N, Tuynder M, Gendron MC, Israël A, Amson R, Oren M, Telerman A (2001) Siah-1 binds and regulates the function of Numb. Proc Natl Acad Sci U S A 98:15067-15072. CrossRef Medline

Thuenauer R, Hsu YC, Carvajal-Gonzalez JM, Deborde S, Chuang JZ, Römer W, Sonnleitner A, Rodriguez-Boulan E, Sung CH (2014) Four-dimensional live imaging of apical biosynthetic trafficking reveals a post-Golgi sorting role of apical endosomal intermediates. Proc Natl Acad Sci U S A 111:4127-4132. CrossRef Medline

Vallazza-Deschamps G, Cia D, Gong J, Jellali A, Duboc A, Forster V, Sahel JA, Tessier LH, Picaud S (2005) Excessive activation of cyclic nucleotidegated channels contributes to neuronal degeneration of photoreceptors. Eur J Neurosci 22:1013-1022. CrossRef Medline

Wang H, den Hollander AI, Moayedi Y, Abulimiti A, Li Y, Collin RW, Hoyng CB, Lopez I, Abboud EB, Al-Rajhi AA, Bray M, Lewis RA, Lupski JR, Mardon G, Koenekoop RK, Chen R (2009) Mutations in SPATA7 cause Leber congenital amaurosis and juvenile retinitis pigmentosa. Am J Hum Genet 84:380-387. CrossRef Medline

Wilson A, Ardiet DL, Saner C, Vilain N, Beermann F, Aguet M, Macdonald HR, Zilian O (2007) Normal hemopoiesis and lymphopoiesis in the combined absence of numb and numblike. J Immunol 178:6746-6751. CrossRef Medline

Zhang Y, Molday LL, Molday RS, Sarfare SS, Woodruff ML, Fain GL, Kraft TW, Pittler SJ (2009) Knockout of GARPs and the beta-subunit of the rod cGMP-gated channel disrupts disk morphogenesis and rod outer segment structural integrity. J Cell Sci 122:1192-1200. CrossRef Medline

Zhong H, Molday LL, Molday RS, Yau KW (2002) The heteromeric cyclic nucleotide-gated channel adopts a 3A:1B stoichiometry. Nature 420:193198. CrossRef Medline

Zhong W, Jiang MM, Schonemann MD, Meneses JJ, Pedersen RA, Jan LY, Jan YN (2000) Mouse numb is an essential gene involved in cortical neurogenesis. Proc Natl Acad Sci U S A 97:6844-6849. CrossRef Medline

Zilian O, Saner C, Hagedorn L, Lee HY, Säuberli E, Suter U, Sommer L, Aguet M (2001) Multiple roles of mouse Numb in tuning developmental cell fates. Curr Biol 11:494-501. CrossRef Medline 